\title{
National Park in the Sahel
}

Michael Kavanagh

Adult female tantalus monkey in Kalamaloue National Park

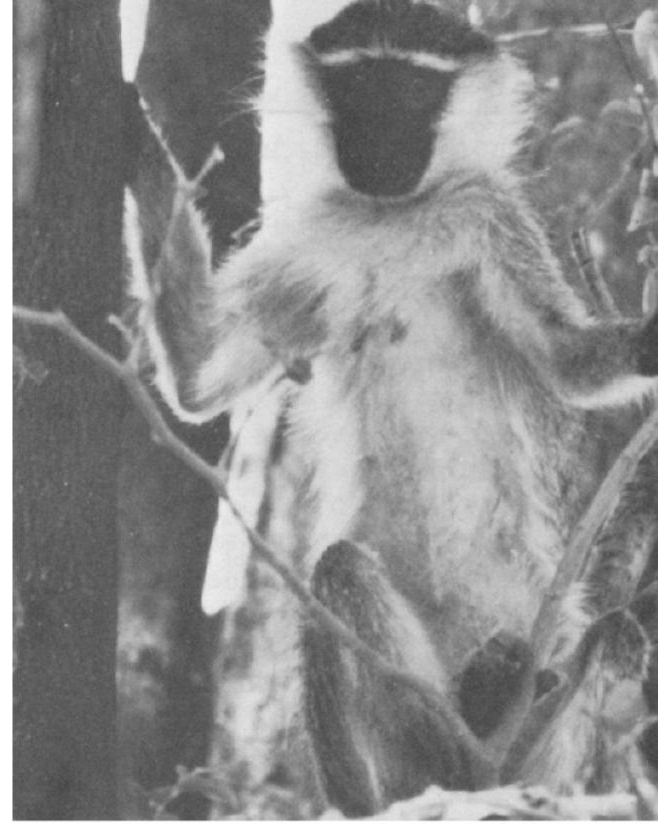

The author suggests that the Kalamaloue National Park in north Cameroon, where he worked in 1974 and 1975, has considerable potential despite its small size. Well populated with a large variety of mammals and birds and, unlike many African parks, safe to walk in, it offers scope for both tourism and scientific research.

Cameroon has a lot to offer in the way of wildlife. The Government has set aside several large areas of the savanna for conservation, and in the forest zone in the south of the country two national parks are being developed. The Waza National Park in the sahelian zone is the best known. Benue and Bouba Njiddah National Parks in the Guinea savanna also attract a steady number of tourists, many of whom stay at the park camps and hunt in the adjacent reserved areas. Much less known is the 2700-ha Parc National de la Kalamaloue in the north, beside the Chari River, where in May/June 1974, I spent four weeks in the course of a comparative study of the behaviour of tantalus monkeys Cercopithecus aethiops tantalus in different habitats. I was also there for much of March, and again from July to October 1975.

Kalamaloue was created a reserve in 1948 and a national park in 1972. It is a strip nearly $15 \mathrm{~km}$ long and just over $2 \mathrm{~km}$ wide, approximately $12 \mathrm{~km}$ west of Kousseri, straddling the main road from Ndjamena in Tchad to Maiduguri in Nigeria, and so close to the Tchadian capital that the glow of the city lights can be seen at night. Climatically it is similar to Waza, both being in the sahelian zone, about $90 \mathrm{~km}$ apart. But in species composition of both flora and fauna they differ considerably. Kalamaloue is unique, with its own fascinating combination of biological, social and economic potential.

\section{Vegetation}

Although such a small park, Kalamaloue can be roughly divided into three 


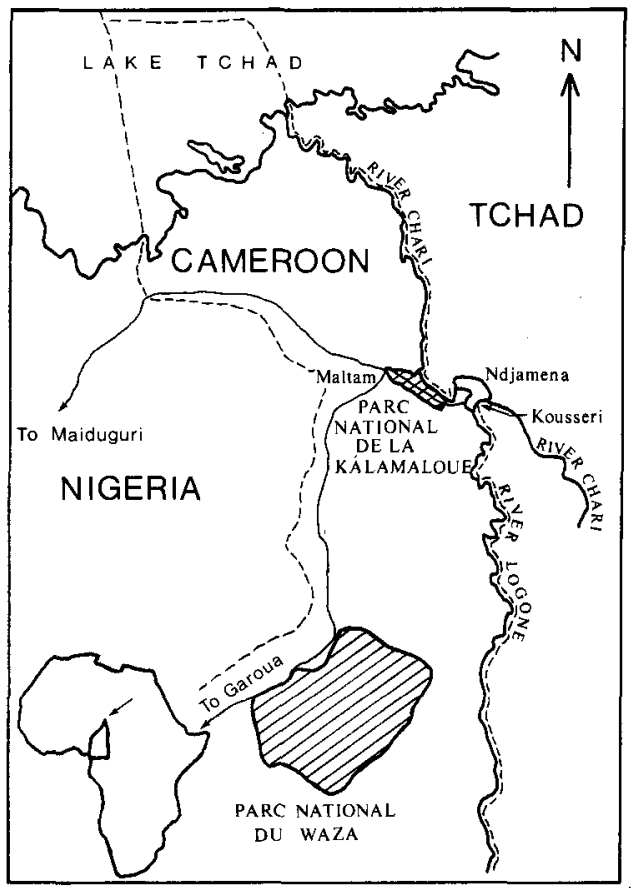

zones. South of the main road is a flat area of open woodland, where Acacia seyal predominates; there is little shade, and towards the end of the dry season, when the ground is bare and cover at a minimum, it becomes unbearably hot by mid-morning. A month of rain, however, can turn it into a green, muddy swamp. North of the main road, the Acacia seyal and stunted open vegetation give way to a belt of taller woodland where $A$. sieberiana, Balanites aegyptiaca, and Tamarindus indica are the main large trees, and Ziziphus spp, Piliostigma reticulata, Ficus spp and Capparis corymbosa are also common. Here too, in the dry season, the ground is bare, but by August, if the rains are generous, the woodland floor is a patchwork of lily ponds surrounded by chest-high grass and herbs. At the northern edge the land slopes down to the Chari Floodplain, which is inundated after the rains, and even in the driest years always has some waterholes. The stands of trees in these open, grassy plains include Mitragyna inermis and Crateva religiosa in the wetter areas. Morelia senegalensis bushes line some watercourses.

Fauna

Birdlife in Kalamaloue is rich. In the daylight hours, the cooing and warbling of many species of pigeons and doves, the constant 'tok-tok-tok-tok' and chatter of guinea-fowl Numida meleagris, and the frequent, metallic cries of long-tailed glossy starlings Lamprotornis caudatus are a background music regularly punctuated by the loud, gull-like cries of the fish-eagles Cuncuma vocifer. At night hyenas whine in chorus, jackals yap and every now and then there comes the unmistakable, sudden bark of a bushbuck.

Other noticeable birds are crowned cranes Balearica pavonina, marabous Leptoptilus crumeniferus, jabirus Ephippiorhynchus senegalensis, rollers Coracias abyssinica and bee-eaters Melittophagus bulocki and Merops nubicus. The commoner mammals include tantalus monkeys Cercopithecus aethiops tantalus and patas Erythrocebus patas, bushbuck Tragelaphus scriptus, Buffon's kob Kobus kob, waterbuck K. defassa, Grimm's duiker Sylvicapra grimmia, warthog Phacochoerus aethiopicus banded mongoose Mungos mungo and ground squirrel Xerus erythropus. Hippopotamus Hippopotamus amphibius can usually be spotted in the Chari, and also commonly seen are jackals, probably Canis aureus and Canis adustus, topi Damaliscus korrigum, Egyptian mongoose Herpestes ichneumon, cape hare Lepus capensis and - for the nocturnal visitor - white-tailed mongoose Ichneumia albicauda. Less often seen are reedbuck Redunca redunca, red-fronted gazelle Gazella rufifrons, 
genet Genetta genetta, wild cat Felis libyca, serval Felis serval, spotted hyaena Crocuta crocuta and sand fox Vulpes pallida.

A small number of giraffe Giraffa camelopardalis have been introduced and in 1974 could be seen occasionally in the dry season, but the following year they had disappeared completely. Late in the 1974 dry season, elephants Loxodonta africana were frequent visitors to the park and made my first night a memorable one when they surrounded the tourist camp and noisily broke up the vegetation; in the morning, dozens of their ghostly forms were moving quietly across the floodplain. Usually they came in from the south-east, crossing the park in a matter of hours and leaving on a north-western heading. A day or so later, elephants - presumably the same ones - would again cross the park, this time in the opposite direction. Sometimes they were in small groups, but more of ten the herds were large, up to 200 strong. They left ample evidence of their passage in broken and barked trees. But in 1975, apart from evidence of the passage of a small group on one occasion, and a single report from a game guard of tracks to the west of the camp, I had no evidence of their presence in the park, and none was seen in the period A pril to June when I was elsewhere. An explanation of this behaviour could be that the 1974 dry season came at the end of a devastating sahelian drought, when water and foliage were scarce, but Kalamaloue, although parched and brown, still had some green leaves in the woodland, and there was water in the Chari and in a waterhole beside the tourist camp. In contrast, in 1975 all of this part of Cameroon, including Kalamaloue, was greener, and waterholes were full where twelve months before they had been dry. Even without an appropriate quantitative study, it was clear that many of the animals in the park behaved differently in the two dry seasons. In 1974, there was a far greater concentration of mammals, especially antelope, warthog, jackal and patas monkeys, in the waterhole near the camp than in 1975.

It seems probable that Kalamaloue and the Chari floodplain to the north of the park provide the elephants with an essential reservoir of both water and edible vegetation in very dry years. People who know the area indicated that these elephants almost certainly came from Waza, about $95 \mathrm{~km}$ to the south. In any case, this would seem to be a fruitful topic for further study, both from the point of view of elephant ecology and behaviour, and to evaluate the ecological importance of Kalamaloue itself.

Other mammals probably present in the park, but which I did not see, include aardvark Orycteropus afer, crested porcupine Hystrix sp., striped hyaena Hyaena hyaena and leopard Panthera pardus. M. Badjoda Douada, the park conservator, saw a single male leopard near the village of Maltam early in 1974, and in 1975 a professional hunter told me he had found leopard tracks in the west of the park. There are no lion Panthera leo. The distant roars I sometimes heard from the direction of Ndjamena came from a caged animal. Certainly, there was no evidence of their presence in the park. Crocodiles Crocodilus niloticus could sometimes be seen in a blind arm of the Chari in the north of the park.

The area outside Kalamaloue is heavily grazed by domestic livestock. Jackals, monkeys and mongooses are occasionally seen there, but the larger species such as antelopes and warthogs have almost disappeared. In 1974, cattle were frequently grazing inside the park, but not the following year, no doubt due to a combination of the constant efforts of the conservator and his 
game guards and the better grazing outside the park. Although a main road runs through Kalamaloue (but is to be re-routed to the south of it), there are no villages inside the park, apart from a small community of about a dozen huts on the Cameroon bank of the Chari at a major crossing-point. The local people frequently walk or bicycle through, using this crossing point. As might be expected, the international border has no effect on this traffic.

The high density of mammals within the park indicates that poaching is not a major problem. Once I heard a lorry stop on the main road, followed by a shot, but by the time a game guard had collected his gun and run the 400 metres to the road, the lorry had driven off again, and it was not clear what, if anything, had been shot. But it was a good illustration of the difficulty of policing even a small park.

\section{Kalamaloue's Potential}

At present, Kalamaloue boasts a single tourist encampment in the centre of the park. There is one boukouru (round house) with two double bedrooms both fully furnished and equipped with showers, and a picnic area with a magnificent view of the Chari floodplain. The staff consists of a caretaker, a game guard and a trainee game guard, all prepared to act as guides. And with a guide it is perfectly safe to walk in Kalamaloue. A network of tracks permits visitors to see most of the park from their vehicles in the dry season, but in the wet season, and when the Chari is in flood, the tracks are impassable even for a Land Rover. However, most of the park can still be seen either on foot or by canoe, so that in practice, Kalamaloue is fully accessible from about January to July. For the rest of the year, the camp and the main road are open to motor vehicles, but to see more than that requires enthusiasm and effort.

Kalamaloue is not well advertised, but it has considerable potential both for overseas tourists (Ndjamena has an international airport) and local people. As a centre for scientific studies it offers a wealth of mammal and bird life, as well as being easily accessible and safe to move about in alone and on foot. Also, within a day's drive to the south is the Ecole pour la Formation des Spécialistes de la Faune at Garoua, where the staff includes experts in ecology, botany, and wildlife management. It is a natural resource with outstanding attractions, great potential for science and for uplifting the quality of the life of those of us who are lucky enough to visit it, and a viable entity. It deserves the appreciation of a wider public.

\section{Acknowledgments}

My work at Kalamaloue was part of a project that could never have been initiated without the aid of Prof. R. J. Andrew, Dr A. Jolly and Dr J. S. Gartlan. In Cameroon, the Hon J. C. Awunti, Vice-minister of Agriculture, and Mr V. Balinga and Mr A. Lima of the Forestry Department graciously helped me in every way they could. I am also grateful to Mr B. Douada, the Conservator of Kalamaloue; Mr A. A. Allo and the staff of L'Ecole pour la Formation des Spécialistes de la Faune, Garoua (especially $\mathrm{Mr}$ C. Geerling who identified plant specimens for me); the director and staff of Projet des Parcs Nationaux, Garoua; British Leyland; and Mr M. E. Ewang who worked with me throughout my study. I also thank Mr C. Atherton for photographic help and Mr. P. Wit for cogent criticism of the manuscript. The project was funded by the Science Research Council.

Dr Michael Kavanagh, Ethology and Neurophysiology Group, Biology Building, University of Sussex, Brighton BN1 9QG. 